\title{
Ductile-Brittle Transition Temperature of Ultrafine Ferrite/ Cementite Microstructure in a Low Carbon Steel Controlled by Effective Grain Size
}

\author{
T. HANAMURA, F. YIN and K. NAGAI \\ National Institute for Materials Science, 1-2-1 Sengen, Tsukuba, Ibaraki 305-0047 Japan. \\ (Received on August 29, 2003; accepted in final form on October 17, 2003)
}

\begin{abstract}
To analyze the good toughness of ultrafine ferrite/cementite steels, the concept of effective grain size $\left(d_{E F F}\right)$ is applied to ductile-to-brittle transition temperature, DBTT, for ultrafine ferrite/cementite (Uf-F/C), ferrite/pearlite (F/P), quenched $(\mathrm{Q})$, and quench-and-tempered (OT) microstructures in a low carbon steel. The $d_{\text {EFF }}$ is determined to be $8,20,100$, and $25 \mu \mathrm{m}$ for Uf-F/C, F/P, Q, and QT, respectively. In F/P and $\mathrm{Q}$, it is in accordance with the ferrite grain size and the prior austenite grain size, respectively. In QT, the $d_{\mathrm{EFF}}$ fits the martensite packet size. In Uf-F/C, the ferrite grain size has a bimodal distribution and the larger grain size corresponds to the $d_{\mathrm{EFF}}$, which is the smallest among the four microstructures. In terms of the relationship between $d_{\mathrm{EFF}}$ and DBTT, the Uf-F/C, $\mathrm{Q}$, and $\mathrm{QT}$ microstructures can be placed into the same group and the F/P to a different one. Furthermore, the Uf-F/C has the highest estimated fracture stress among the four microstructures. These might be the result of the difference in the surface energy of fracture, namely the former is estimated to have a surface energy of $34.6 \mathrm{~J} / \mathrm{m}^{2}$ and latter a surface energy of $7.7 \mathrm{~J} / \mathrm{m}^{2}$. Thus, the excellent toughness of the ultrafine ferrite/cementite steel can be attributed to the small $d_{\mathrm{EFF}}$ and the high surface energy of fracture.
\end{abstract}

KEY WORDS: effective grain size; ductile-to-brittle transition temperature; toughness; fracture strength; low carbon steel; ultrafine grain structure.

\section{Introduction}

A major concern for structural materials has been the improvement of the trade-off balance between strength and toughness. The balance between yield strength, YS, and ductile-to-brittle temperature, DBTT, has attracted a great attention from an engineering point of view. In this aspect, Pickering ${ }^{1)}$ derived the balance vectors with respect to the strengthening mechanism from his collected database for low carbon steels with ferrite grain sizes larger than $10 \mu \mathrm{m}$, and pointed out the great significance of grain refinement. As shown in Fig. 1, the change of DBTT by a $9.8 \mathrm{MPa}$ increase in $\mathrm{YS}$ is $+6 K$ in dislocation strengthening, $+4 K$ in dispersion strengthening, and $-10 K$ in grain-size strengthening.

In ferrite/pearlite, F/P, low carbon steels, DBTT can be determined by the crystallographic ferrite grain size, $d$, and expressed in the following forms ${ }^{1-4)}$.

$$
\begin{aligned}
\mathrm{DBTT} & =A-K d^{-1 / 2} \quad \text { or } \\
& =A-K \ln d^{-1 / 2} \ldots
\end{aligned}
$$

where the constant $A$ contains metallurgical factors other than the grain size and the coefficient $K$ is independent of grain size.

The ultrafine ferrite/cementite, Uf-F/C, steel shows an excellent balance of high YS and low DBTT as expected. However, the above-mentioned equation is not necessarily applicable ${ }^{5)}$ when the ferrite grain size is taken as $d$. In other words, the value of DBTT varies widely between Eqs. (1) and (2) when a grain size in the range of a few $\mu \mathrm{m}$ and smaller is used. The DBTT estimated with $d=1 \mu \mathrm{m}$ from Eq. (1) is $49 K$, while that from Eq. (2), based on the extrapolation of the experimental data from reference, ${ }^{6}$ is $104 \mathrm{~K}$.

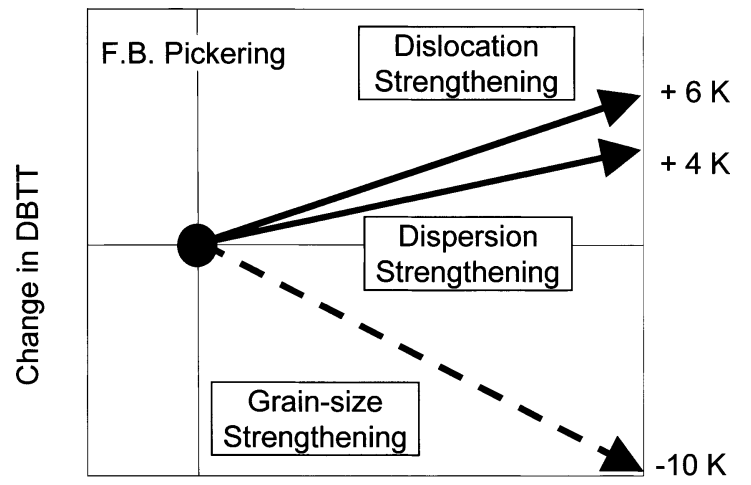

Change of 9.8 MPa in Yield Strength

Fig. 1. Relationship between the change in DBTT and the change of $9.8 \mathrm{MPa}$ in yield strength for different microstructural factors, i.e. dislocation strengthening, dispersion strengthening, and grain-size strengthening. 
The $9 \%$ Ni steel is an excellent material with a good balance of strength and toughness. ${ }^{7}$ The microstructure is a quench and tempered (QT) martensite that occasionally contains a small volume of retained austenite. Its high YS is inherent to the QT martensite, since Ni addition does not increase YS by itself. Hence, the specific effect of Ni is to enhance the toughness of QT steel, whose mechanism is still disputable. In QT steel, the idea of an effective grain size, ${ }^{8)} d_{\mathrm{EFF}}$, accounts for the DBTT in the steel (Terasaki et al. use the term, unit crack path, ${ }^{9)}$ instead of effective grain size).

The Griffith idea says that fracture stress, $\sigma_{\mathrm{F}}$, is a function of the surface energy of fracture and an imaginary crack size. The unstable growth of the Griffith crack has been discussed by assuming that the imaginary pre-existing crack interacting with the stress field in the transition temperature range is comparable to the size of the ferrite grain. ${ }^{10)}$ Under the same stress field in the transition temperature range, plastic deformation prevails over brittle fracture when yielding occurs first or the brittle fracture dominates when the cleavage starts before yielding. Since a criterion to initiate yielding in polycrystalline material is the grain size or slip length, it is simple and reasonable to suppose that the cleavage cracking of a grain is a counter measure to initiate cleavage fracture. However, such a "grain" idea is not always evident in all the steel mi-

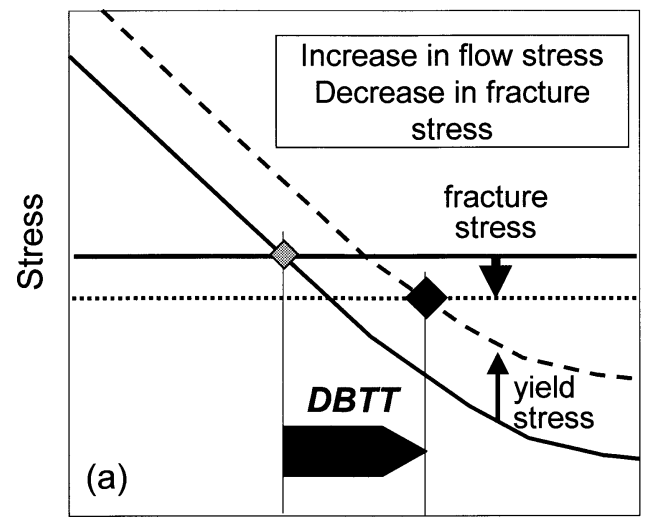

Temperature

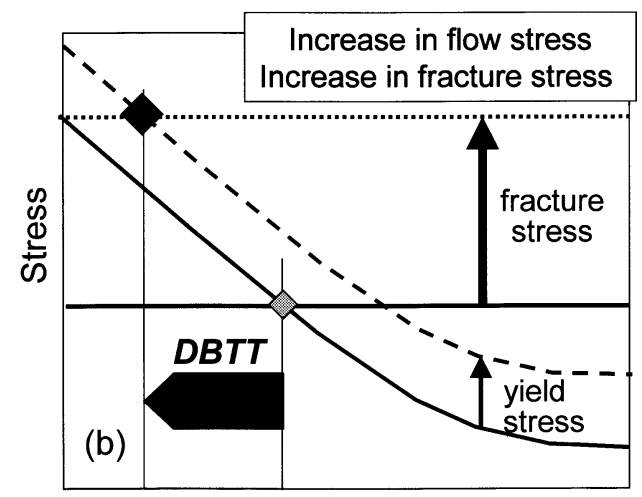

Temperature

Fig. 2. (a) Schematic relationship among yield stress, fracture stress, and DBTT: in the case, where a further increase in DBTT occurs when the increase in YS decreases $\sigma_{\mathrm{F}}$. (b) Schematic relationship among yield stress, fracture stress, and DBTT: in the case, where a further decrease in DBTT occurs when the increase in YS significantly increases $\sigma_{\mathrm{F}}$ crostructures.

The brittle fracture belongs to a similar family of transgranular cleavage in bcc steels. In F steel, its brittle fracture is a typical cleavage of the $\{100\}_{\alpha}$ plane. ${ }^{11)}$ Furthermore, the cleavage planes have also been identified as $\{100\}_{\alpha}{ }^{12-14)}$ in F/P, QT, and Uf-F/C steels. Hence, we can finally understand that $d_{\mathrm{EFF}}$, in which a cleavage crack goes through in a straight fashion, corresponds to the microstructural unit having a specific crystallographic orientation and bounded by high-angle boundaries. In addition, the $d_{\mathrm{EFF}}$ can be determined experimentally by fractography.

Flow stress increases at lower temperatures. Fracture stress, $\sigma_{\mathrm{F}}$, which is assumed to be equal to the flow stress at DBTT, is believed to be not dependent on temperature. Hence, an increase in flow stress or that in YS increases the temperature at which the flow stress reaches $\sigma_{\mathrm{F}}$, or shifts the DBTT to a higher temperature. In addition, a further increase in DBTT may occur when the increase in YS decreases $\sigma_{\mathrm{F}}$, as described in Fig. 2(a). ${ }^{1)}$ Unless the grain refinement increases $\sigma_{\mathrm{F}}$ significantly, the shifting of DBTT to a lower temperature cannot be accounted for as demonstrated in Fig. 2(b). Thus, the reasons that Uf-F/C can generate the excellent toughness should also be considered in terms of $\sigma_{\mathrm{F}}$.

Hence, we fabricated four different microstructures from a single steel with a low carbon content in the present study and extensively examined how DBTT is determined for each microstructure with the aid of an $d_{\mathrm{EFF}}$ idea, paying special attention to the excellent toughness of the Uf-F/C steel. Recently, the Uf-F/C has sometimes been shown to have bimodal structures, i.e. two peaks exist in the grain size distribution. ${ }^{14)}$ Hence, it is also interesting to determine which crystallographic unit mainly controls the DBTT in the Uf-F/C structure.

\section{Experimental}

An ingot was melted in vacuum in a laboratory scale. The chemical composition analogous to the conventional JIS-SM490 is shown in Table 1. The ingot was homogenized for $1800 \mathrm{~s}$ at $1473 \mathrm{~K}$ and hot-rolled to a $23 \mathrm{~mm}$-thick plate. (1) F/P samples were machined from the plate. (2) Uf-F/C samples were made from the plate in the following manner: The plate was heated for $1800 \mathrm{~s}$ at $1173 \mathrm{~K}$, followed by water quenching, and then caliber-warm-rolled into $12 \mathrm{~mm}$-square and $1000 \mathrm{~mm}$-long rods by an accumulated area reduction of $85 \%$. (3) Q, designating asquenched, samples were the Uf-F/C samples annealed for $3600 \mathrm{~s}$ at $1373 \mathrm{~K}$ and water quenched. Finally, (4) QT samples were obtained by tempering the $Q$ samples for $3.6 \times 10^{5}$ s at $723 \mathrm{~K}$.

Cylindrical tensile test pieces were machined from four samples with a gage diameter of $3.5 \mathrm{~mm}$ and a gage length

Table 1. Chemical compositions of the steel.

( $\operatorname{mass} \%$ )

\begin{tabular}{|c|c|c|c|c|c|c|c|}
\hline & $\mathrm{C}$ & $\mathrm{Si}$ & $\mathrm{Mn}$ & $\mathrm{P}$ & $\mathrm{S}$ & $\mathrm{T}-\mathrm{Al}$ & $\mathrm{T}-\mathrm{N}$ \\
\hline Present & 0.148 & 0.33 & 1.41 & 0.001 & 0.001 & 0.003 & 0.0012 \\
\hline SM490 & 0.15 & 0.28 & 1.45 & 0.005 & 0.0004 & 0.031 & 0.0016 \\
\hline
\end{tabular}


of $25 \mathrm{~mm}$. The direction of the tensile test pieces was parallel to the rod length. Charpy impact test pieces were similarly prepared in a standard $10 \mathrm{~mm}$-square, $55 \mathrm{~mm}$-long, and $2 \mathrm{~mm}$ V-notched geometry. The length of the Charpy impact test pieces was parallel to the rod length and the notch was vertical to both the rod length and one of the four flanks of the rod. Tensile tests were performed with a crosshead speed of $0.5 \mathrm{~mm} / \mathrm{min}$ at room temperature, and Charpy impact tests were conducted in the temperature range between $78 \mathrm{~K}$ and $373 \mathrm{~K}$.

Samples from the Charpy impact test were observed with an optical microscope (OM), a scanning electron microscope (SEM), an electron backscatter diffraction measure-

(a)
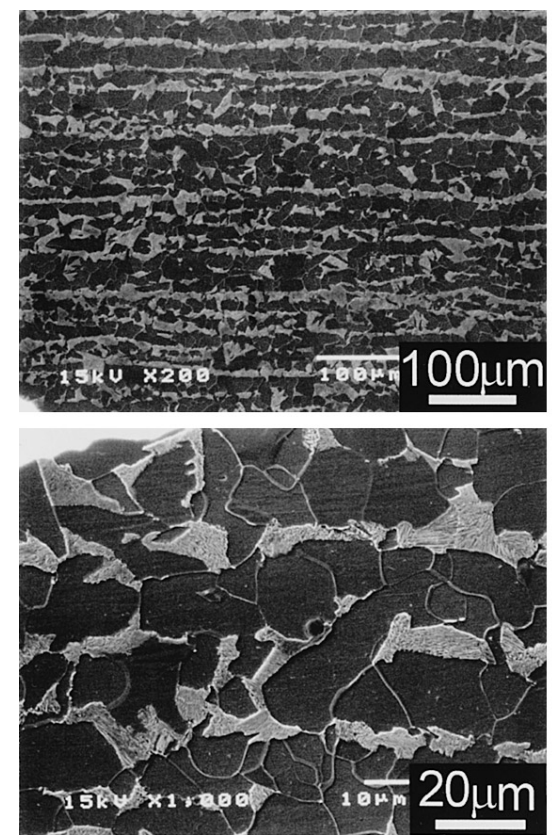

(c)
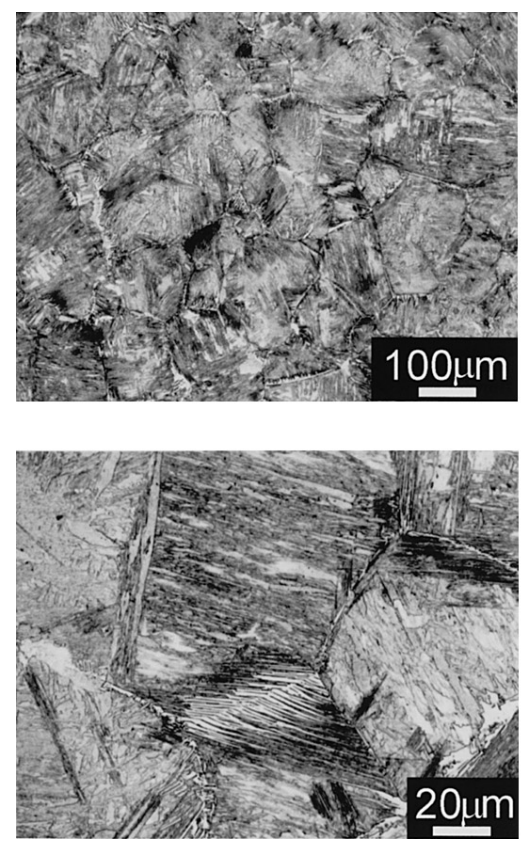

ment (EBSD) and a transmission electron microscope (TEM). The $d_{\mathrm{EFF}}$ was determined by measuring the cleavage fracture unit of each sample fractured at $77 \mathrm{~K}$. Each fractured sample was cut in half, embedded into a plastic mold, and observed by SEM.

\section{Results}

\subsection{Microstructure}

Figure 3 shows SEM microstructures for all the samples. In the F/P sample, the horizontal and the normal directions are parallel and perpendicular to the hot-rolling direction, respectively. In the other samples, the normal direction is (b)
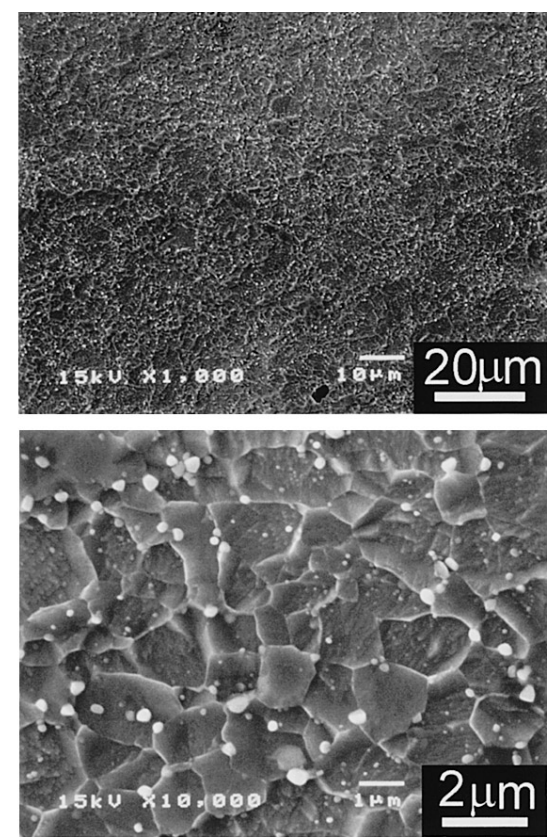

(d)
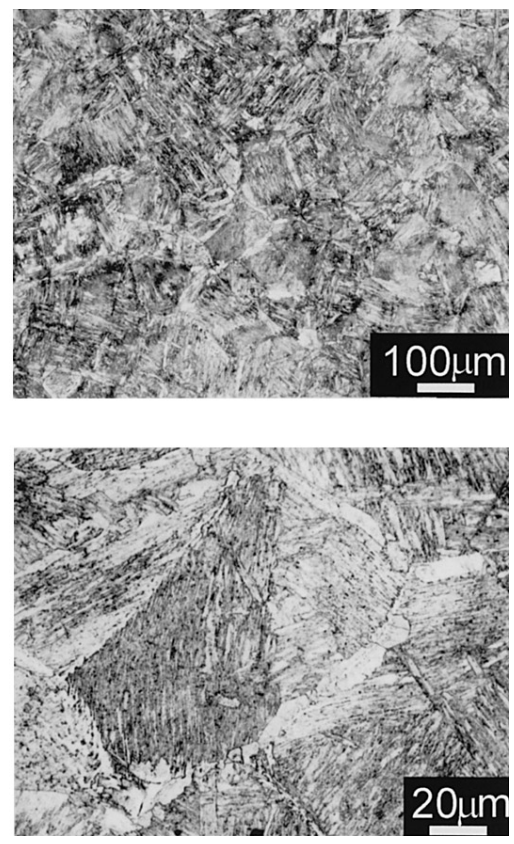

Fig. 3. Microstructures of (a) ferrite/pearlite (F/P), (b) ultrafine ferrite/cementite (Uf-F/C), (c) as-quenched (Q), (d) quench-and-tempered (QT) steels. 
(a)

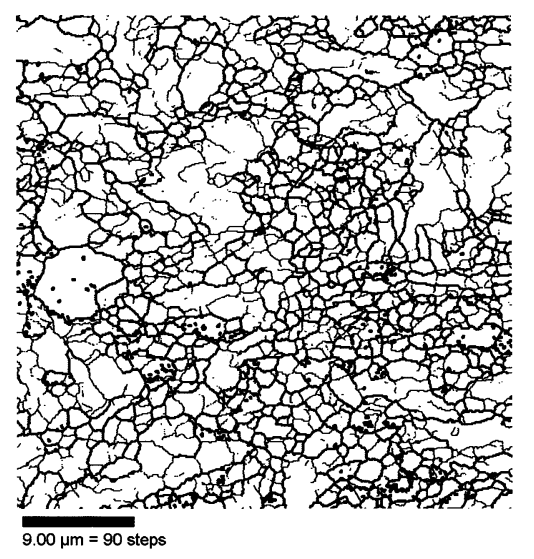

(b)

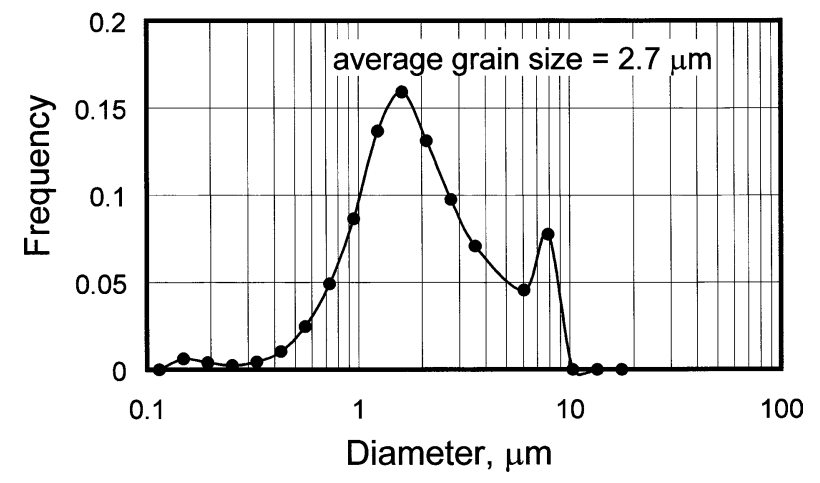

Fig. 4-1. EBSD analysis on the ultrafine ferrite/cementite (UfF/C) steel. (a) The ferrite grains manifested by the boundaries with the misorientation above 5 degrees (the difference in crystallographic orientation is 5 degrees and more), (b) the grain size and misorientation distribution caluculated on the analysis.

identical to the caliber-rolling direction or the cross sectional area is shown.

The F/P (a) consists of ferrite and pearlite. White parts correspond to the pearlite and gray parts to the ferrite. The average ferrite grain size is $20 \mu \mathrm{m}$.

The Uf-F/C (b) consists of equiaxed ultrafine grain microstructures and finely dispersed cementites, according to SEM observations. White dots correspond to the cementites and gray parts to the ferrite. The ferrite grains were elongated to some extent in the longitudinal direction. On the other hand, the EBSD analysis also characterized the grain boundaries in the Uf-F/C sample, as shown in Fig. 4-1. In this figure, the ferrite grains are manifested by the boundaries with the misorientation above 5 degrees. There are two kinds of characteristic ferrite grains with a peak area fraction in the microstructure, i.e. the fine ones (about $1.6 \mu \mathrm{m}$ ), and the coarse ones (about $8 \mu \mathrm{m}$ ). ${ }^{15)}$ The average grain size determined by grain area averaging, including the two kinds of characteristic grain sizes, is $2.7 \mu \mathrm{m}$.

The Q (c) has a structure mostly consisted of martensite, while the QT (d) has a structure mostly consisted of tempered martensite. The large unit corresponds to the prior austenite grain. The prior austenite grain size for both samples is determined to be about $100 \mu \mathrm{m}$. The EBSD analysis cannot be applied to the Q sample because of the large strains in the matrix that prevent precise EBSD measurements. On the other hand, the detailed microstructure of the (a)

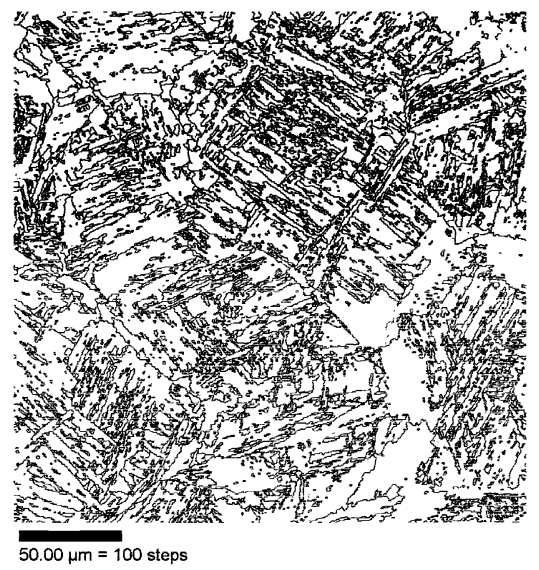

(b)

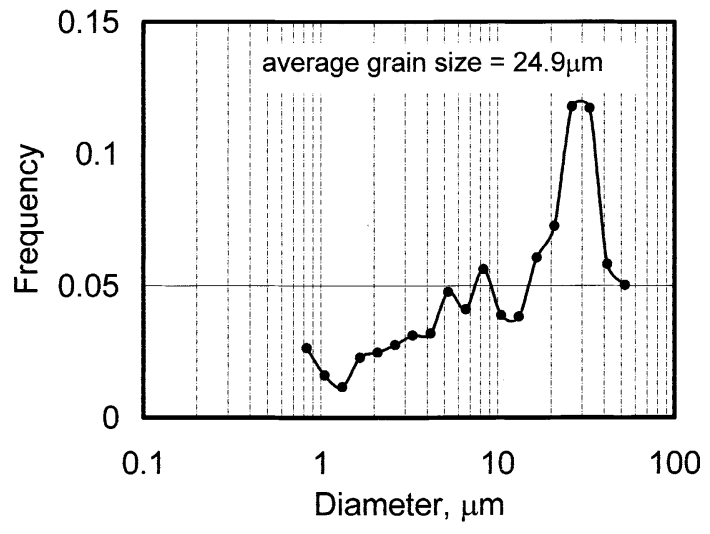

Fig. 4-2. EBSD analysis on the quench-and-tempered (QT) steel. (a) The ferrite grains manifested by the boundaries with the misorientation above 5 degrees (the difference in crystallographic orientation is 5 degrees and more), (b) the grain size and misorientation distribution caluculated on the analysis.

Table 2. Properties of the steel with different microstructures, i.e. ferrite/pearlite $(\mathrm{F} / \mathrm{P})$, ultra-fine ferrite/cementite (Uf-F/C), as-quenched (Q), and quench-and-tempered (QT) steels: YS (yield strength), TS (tensile strength), T.El. (total elongation), and U.El. (uniform elongation).

\begin{tabular}{|c|c|c|c|c|}
\hline Sample & YS(MPa) & TS(MPa) & T.EL(\%) & U.EL(\%) \\
\hline F/P & 261 & 463 & 35 & 16.0 \\
\hline Uf-F/C & 536 & 612 & 21 & 9.5 \\
\hline Q & 619 & 1027 & 4 & 2.9 \\
\hline QT & 548 & 676 & 17 & 7.4 \\
\hline
\end{tabular}

QT shows the interior of the prior austenite grain, where the fine martensite laths and fine cementite particles can be seen. The EBSD analysis also characterized the grain boundaries in the QT sample, and the grains are manifested by the boundaries with the misorientation above 5 degrees, as shown in Fig. 4-2. There are grains with a peak area fraction in the microstructure with a size of about $25 \mu \mathrm{m}$, which corresponds to the packet size.

\subsection{Charpy Impact Property}

YS, TS, total elongation, T.El., and uniform elongation, U.El., for each structure are listed in Table 2.

The Charpy impact absorbed energy as a function of test temperature for the four samples is plotted in Fig. 5. The Q 
sample shows the poorest impact properties among them. The upper shelf energy cannot be determined even at $373 \mathrm{~K}$. The QT shows improved properties of $240 \mathrm{~K}$ for the absorbed energy transition temperature and $240 \mathrm{~J}$ for the upper-shelf energy. The F/P shows a lower absorbed energy transition temperature and a higher upper-shelf energy than those of the QT. The Uf-F/C has the best impact properties, having the lowest absorbed energy transition temperature of $160 \mathrm{~K}$ and maintaining the high upper-shelf energy level of $300 \mathrm{~J}$ down to $230 \mathrm{~K}$.

The change of crystallinity, or the area percent of brittle fracture on the fracture surface, measured by fractography is plotted as a function of temperature in Fig. 6. DBTT is defined as the temperature having $50 \%$ crystallinity. The DBTT for the four samples is as follows: $53 \mathrm{~K}$ for $\mathrm{UfF} / \mathrm{C}$, $223 \mathrm{~K}$ for $\mathrm{F} / \mathrm{P}, 253 \mathrm{~K}$ for QT, and $378 \mathrm{~K}$ for Q samples.

Figure 7 shows the SEM image of the side view of the

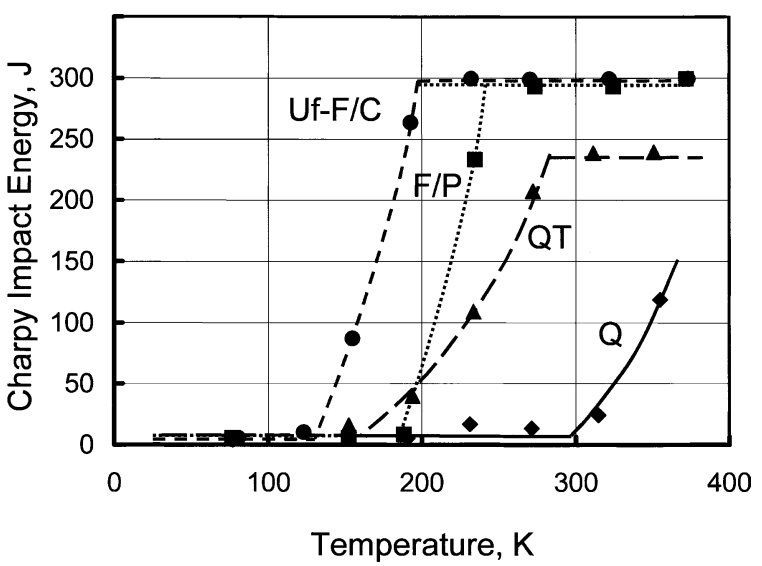

Fig. 5. Charpy impact absorbed energy as a function of test temperature for ferrite/pearlite $(\mathrm{F} / \mathrm{P})$, ultra-fine ferrite/cementite (Uf-F/C), as-quenched $(\mathrm{Q})$, and quench-and-tempered (QT) steels.
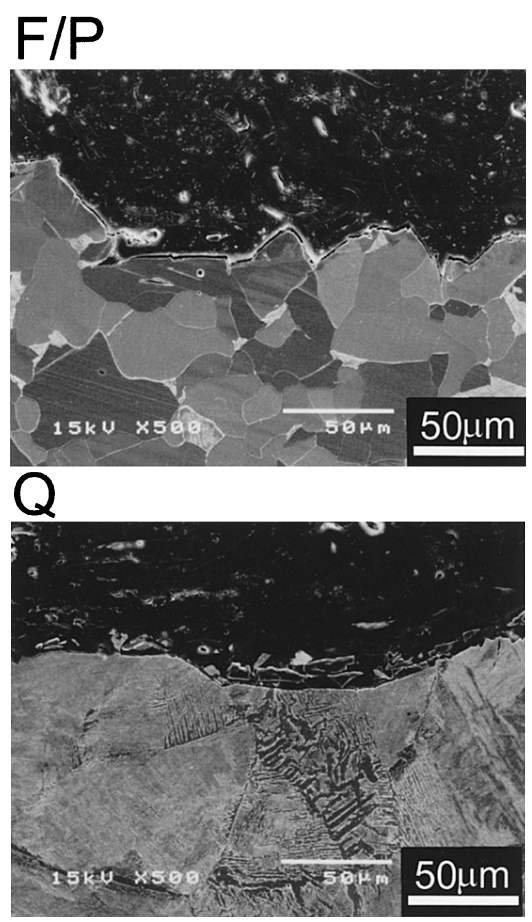

fracture surface for each sample tested at $77 \mathrm{~K}$. The crack path is from the right to the left, with the V-notch at the right end. Therefore, the fracture surface is observed as a line at the top-edge side view of the sample. $d_{\mathrm{EFF}}$ is determined to be $8,20,100$, and $25 \mu \mathrm{m}$ for Uf-F/C, F/P, Q, and $\mathrm{QT}$, respectively. In $\mathrm{F} / \mathrm{P}$ and $\mathrm{Q}$, it is in good accordance with the ferrite grain size and the prior austenite grain size, respectively. In QT, the $d_{\mathrm{EFF}}$ of $25 \mu \mathrm{m}$ fits with the martensite packet size in the tempered structure. The reason why the $d_{\mathrm{EFF}}$ value is different between Q and QT might be due to be the relaxation of strain and the rotation of crystallographic grain direction because of annealing. The $d_{\mathrm{EFF}}$ of 8 $\mu \mathrm{m}$ for Uf-F/C corresponds to the larger grain size in the bimodal distribution.

Figure 8 shows the relationship between the $d_{\mathrm{EFF}}$ and DBTT, including the literature data for QT steels, ${ }^{9)} \mathrm{F} / \mathrm{P}$

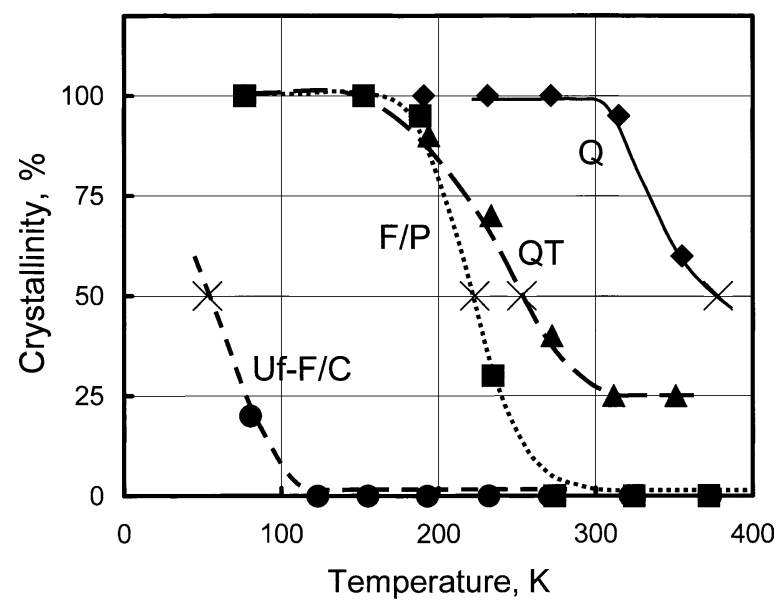

Fig. 6. Crystallinity after Charpy impact test as a function of test temperature for ferrite/pearlite (F/P), ultra-fine ferrite/cementite (Uf-F/C), as-quenched (Q), and quench-and-tempered (QT) steels.
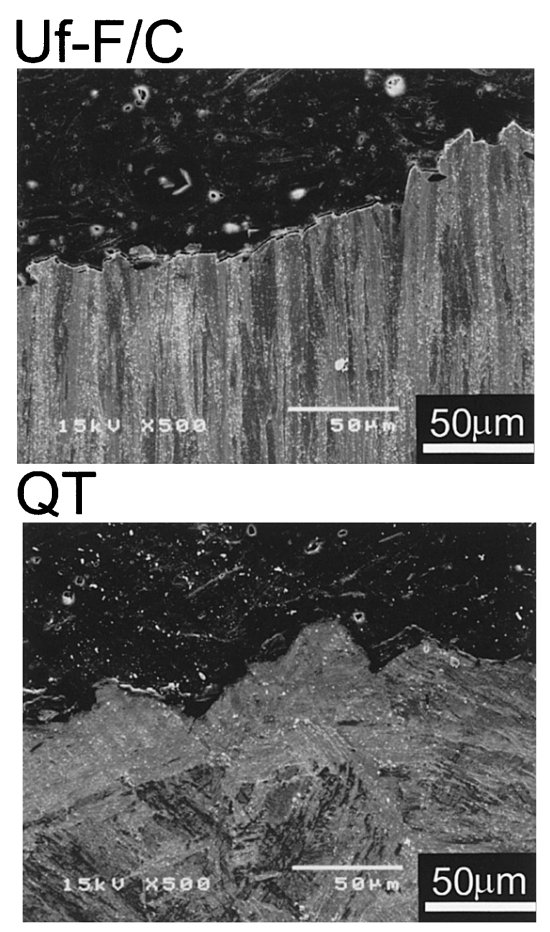

Fig. 7. SEM micrographs of cleavage fracture unit for ferrite/pearlite (F/P), ultra-fine ferrite/cementite (Uf-F/C), asquenched (Q), and quench-and-tempered (QT) steels. 


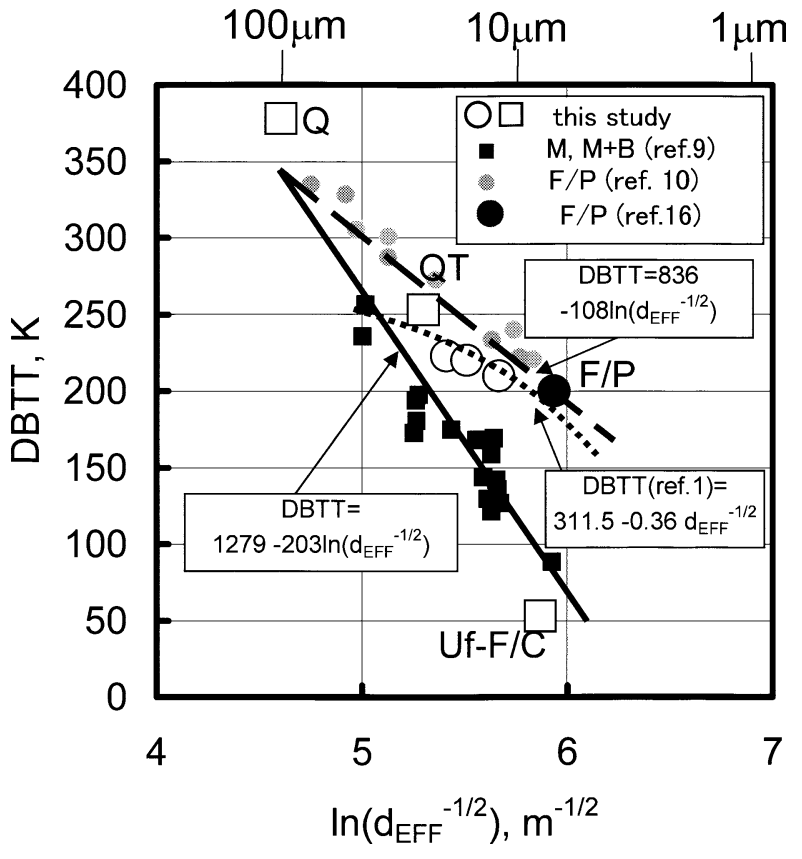

Fig. 8. Relationship between effective grain size and DBTT for the steels in this study, $\mathrm{M}$ and $\mathrm{M}+\mathrm{B}$ steels $^{9)}$ and a $\mathrm{F} / \mathrm{P}$ steel. $^{10,16)}$

steels $(0.15 \mathrm{C}-0.26 \mathrm{Si}-1.44 \mathrm{Mn}),{ }^{10)}$ and another $\mathrm{F} / \mathrm{P}$ steel (SM490: $0.15 \mathrm{C}-0.48 \mathrm{Si}-1.48 \mathrm{Mn}){ }^{16)}$ The F/P steel of Ref. 16) had an average grain size of $7 \mu \mathrm{m}$ and a DBTT of $200 \mathrm{~K}$. Here, the data of two $\mathrm{F} / \mathrm{P}$ samples with different grain sizes of 12 and $16 \mu \mathrm{m}$ were also added. These two samples were prepared by heating the Uf-F/C sample at different temperatures in the austenite phase region and then by cooling them in the ferrite/pearlite structure. In this figure, two groups seem to exist, a group belonging to the F/P microstructure and the other to the Q, QT, and Uf-F/C microstructures. The important points in this figure are that the smallest $d_{\mathrm{EFF}}$ of Uf-F/C results in the lowest DBTT in the latter group. Furthermore, the Uf-F/C shows a lower DBTT at a given $d_{\mathrm{EFF}}$ than the F/P group.

Accordingly, when $d$ in Eq. (2) is replaced by effective grain size, $d_{\mathrm{EFF}}$, DBTT can be expressed by the following equation:

$$
\mathrm{DBTT}=A-B \cdot \ln \left(d_{\mathrm{EFF}}^{-1 / 2}\right) .
$$

Here, $A$ and $B$ are 1279, 203 for the Q, QT, and Uf-F/C group and 836, 108 for the $\mathrm{F} / \mathrm{P}$ group. The unit is $\mathrm{K}$ for DBTT and $\mathrm{m}$ for $d_{\mathrm{EFF}}$.

In Fig. 8, the estimation on the change of DBTT by $d_{\mathrm{EFF}}$ is also superimposed using Eq. (1) by Pickering ${ }^{1)}$ :

$$
\begin{aligned}
\mathrm{DBTT}= & 254+44(\mathrm{Si})+700\left(\mathrm{~N}_{\mathrm{f}}\right)^{-1 / 2} \\
& +2.2(\text { Pearlite })-0.36 d^{-1 / 2}
\end{aligned}
$$

with $\mathrm{Si}=0.3 \%, \mathrm{~N}_{\mathrm{f}}=0 \%$, Pearlite $=20 \%$. Finally $A$ becomes 311.5 and $B 0.36$ in the form of Eq. (1). Here, $(\mathrm{Si})$ and $\left(\mathrm{N}_{\mathrm{f}}\right)$, are the mass percentages of $\mathrm{Si}$ and $\mathrm{N}$ in the matrix, respectively. (Pearlite) is the volume percent of pearlite. The unit of $d$ is $\mathrm{m}$. The estimated curve is close to the $\mathrm{F} / \mathrm{P}$ group data in the present study. However, the extrapolated curve shows that the DBTT of F/P is lower than that of the present study, suggesting that the Pickering's estimation is applicable only in the range around $10 \mu \mathrm{m}$. For grain sizes be-

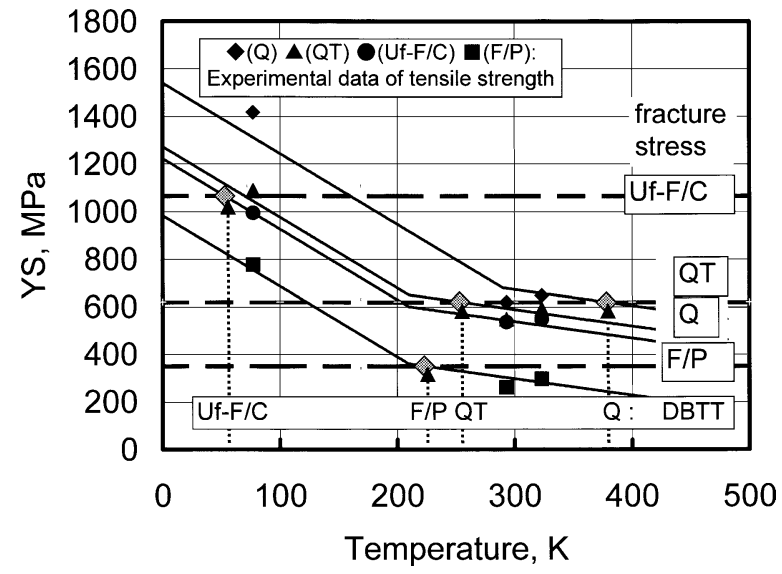

Fig. 9. Relationship between flow stress and $\sigma_{\mathrm{F}}$ as a function of temperature based on experimental data for different microstructures.

tween 100 and $7 \mu \mathrm{m}$, the equation obtained in this study along with the data from Refs. 10) and 16), e.g. Eq. (3) with $A=836$ and $B=108$, agrees better with the presented data.

\section{Discussion}

\subsection{Estimation of Fracture Stress}

Fracture stress is a function of the surface energy of fracture, $\gamma$, and the crack size, $r$, according to the Griffith equation $^{17)}$ when considering an infinite cracked plate with a central transverse crack of length $r$ :

$$
\sigma_{\mathrm{F}}=(4 \gamma E / \pi)^{1 / 2} \cdot r^{-1 / 2}
$$

Here we replace $r$ by $d_{\mathrm{EFF}}$ :

$$
\sigma_{\mathrm{F}}=(4 \gamma E / \pi)^{1 / 2} \cdot d_{\mathrm{EFF}}^{-1 / 2}
$$

On the other hand, when we assume an infinite plate with a penny shaped crack of diameter $r$ in the bulk center, the fracture stress is expressed like the following ${ }^{17)}$ :

$$
\sigma_{\mathrm{F}}=\left(\pi \gamma E /(v-1)^{2}\right)^{1 / 2} \cdot r^{-1 / 2}
$$

Here we replace $r$ by $d_{\mathrm{EFF}}$ :

$$
\sigma_{\mathrm{F}}=\left(\pi \gamma E /(v-1)^{2}\right)^{1 / 2} \cdot d_{\mathrm{EFF}}^{-1 / 2}
$$

When we assume that $\sigma_{\mathrm{F}}$ is independent of temperature and becomes equal to the flow stress at DBTT, we can estimate the $\sigma_{\mathrm{F}}$ by taking the YS as the flow stress at DBTT as described below.

According to N. Tsuchida et al., ${ }^{18)}$ the thermal component of flow stress is independent of ferrite grain size while the athermal component increases with decreasing grain size. Therefore, in Fig. 9, the change of flow stress by temperature obtained by Tsuchida et al. is adopted and drawn parallel to each sample as each curve has the YS determined at three different temperatures, i.e. 77, 293, and $323 \mathrm{~K}$. However, in the sample Q, the curve is offset to higher temperature regions to fit the experimental data of YS. This is done by assuming that the change in YS for sample Q has the same shape as those of F/P samples, except with a different temperature, at which the curve changes its inclination. The marks, $\mathbf{\square}, \boldsymbol{\bullet}, \boldsymbol{\Delta}, \boldsymbol{\Delta}$ stand for the YS for F/P, Uf-F/C, Q, and QT, respectively. The large meshed diamond $(\diamond)$ is the YS at DBTT for each sample, 
or in other words the estimated $\sigma_{\mathrm{F}}$. The horizontal line shows the $\sigma_{\mathrm{F}} v s$. temperature curve for each sample.

The difference between $\sigma_{\mathrm{F}}$ and YS for each microstructure is $440 \mathrm{MPa},-18 \mathrm{MPa}$, and $-90 \mathrm{MPa}$ at room temperature for $\mathrm{Uf}-\mathrm{F} / \mathrm{C}, \mathrm{Q}$, and $\mathrm{QT}$, respectively, while $\mathrm{F} / \mathrm{P}$ is taken as the reference. This clearly shows that Uf-F/C has the largest difference between $\sigma_{\mathrm{F}}$ and YS among the four microstructures. Hence, the earlier speculation that the grain refinement increases the $\sigma_{\mathrm{F}}$ significantly is proved.

\subsection{Estimation of Surface Energy of Fracture}

Using Eqs. (6) and (8), we can also estimate the surface energy of the fracture for each sample with the estimated $\sigma_{\mathrm{F}}$ and the experimentally determined $d_{\mathrm{EFF}}$. In this estimation by using Eqs. (6) and (8), $E$ is taken as $2.06 \times 10^{2} \mathrm{GPa}$ and $v$ is taken as 0.293 as for steel.

When $\sigma_{\mathrm{F}}$ determined by Eq. (6) is plotted against $d_{\mathrm{EFF}}$, and we can find three groups similarly as in Fig. 8. The slope of each group shows the surface energy of fracture. The first group consists of only F/P samples with the lowest estimated surface energy of $7.7 \mathrm{~J} / \mathrm{m}^{2}$, the second group of $\mathrm{Uf}-\mathrm{F} / \mathrm{C}$ and QT with an estimated surface energy of $34.6 \mathrm{~J} / \mathrm{m}^{2}$, and the third group of Q with a surface energy of $150.9 \mathrm{~J} / \mathrm{m}^{2} . \sigma_{\mathrm{F}}$ determined by Eq. (8) can also be used to estimate the surface energy of each sample, and we can find three groups. In this case, the first group consists of only $\mathrm{F} / \mathrm{P}$ samples with the lowest estimated surface energy of $1.5 \mathrm{~J} / \mathrm{m}^{2}$, the second group of Uf-F/C and QT with an estimated surface energy of $7.0 \mathrm{~J} / \mathrm{m}^{2}$, and the third group of $\mathrm{Q}$ with a surface energy of $29.7 \mathrm{~J} / \mathrm{m}^{2}$.

The surface energy of ferrite iron is presented to be

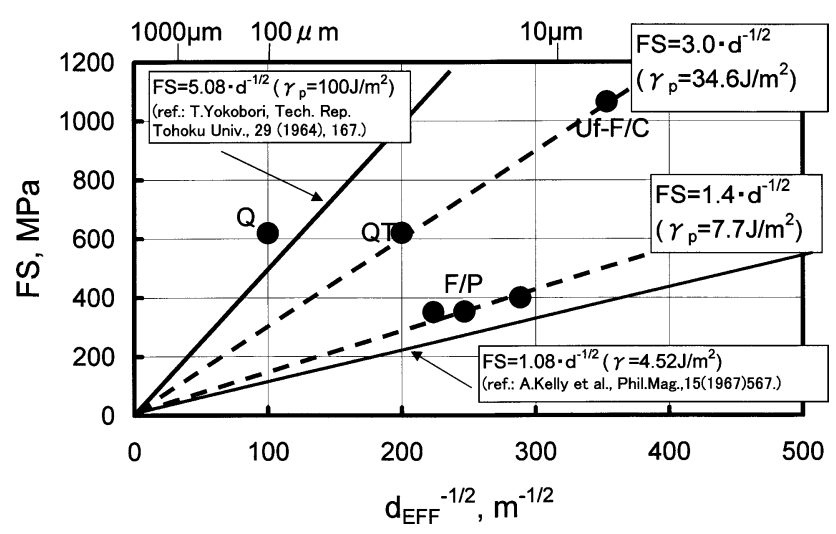

Fig. 10. $\sigma_{\mathrm{F}}$ as a function of the inverse square root of effective grain size for different microstructures.
$4.52 \mathrm{~J} / \mathrm{m}^{2}$ by A. Kelly et al. ${ }^{19)} \mathrm{T}$. Yokobori et al. ${ }^{20)}$ reported that an experimental value of effective surface energy is $100 \mathrm{~J} / \mathrm{m}^{2}$. In Fig. 10, $\sigma_{\mathrm{F}}$ determined by Eq. (6) is plotted against $d_{\mathrm{EFF}}$, together with lines constructed using the value of surface energy of Refs. 19) and 20). The surface energy together with $d_{\mathrm{EFF}}$, the unit of structure determining the $d_{\mathrm{EFF}}, \mathrm{YS}, \sigma_{\mathrm{F}}$, and DBTT are listed in Table 3.

Interestingly $\mathrm{Uf}-\mathrm{F} / \mathrm{C}$ is concluded to have a higher surface energy than F/P. This means that Uf-F/C can have a lower DBTT than F/P due to its higher surface energy of fracture and the resultant higher fracture stress when Uf$\mathrm{F} / \mathrm{C}$ has the same $d_{\mathrm{EFF}}$ as F/P.

Accordingly the excellent toughness or a very low DBTT of Uf-F/C can be attributed to its small $d_{\mathrm{EFF}}$ and high surface energy of fracture.

\subsection{Bimodal Distribution of Grain Size in Uf-F/C}

There are three kinds of grain sizes in the present Uf$\mathrm{F} / \mathrm{C}$, i.e. 1.6 and $8 \mu \mathrm{m}$ for the peaks of distribution, and $2.7 \mu \mathrm{m}$ for the area average determined by EBSD. One way to determine the grain size of a microstructure is by the linear intercept method based on OM or SEM images. Another way is grain area averaging based on the EBSD images using different angle values of grain boundaries. Among the high angle grain boundaries, those with boundary angles equal to or above 5 degrees are said to be effective for the clarification of grain sizes. ${ }^{21,22)}$ In the Uf-F/C, the larger grain cluster, i.e. the $8 \mu \mathrm{m}$ grain cluster, corresponds to the $d_{\mathrm{EFF}}$.

Tsuchida et $_{\text {al. }}{ }^{23)}$ reported that YS is estimated to be 551 $\mathrm{MPa}$ for $1.6 \mu \mathrm{m}, 464 \mathrm{MPa}$ for $2.7 \mu \mathrm{m}$, and $342 \mathrm{MPa}$ for $8 \mu \mathrm{m}$ when Uf-F/C is annealed after caliber rolling. Yin et $a l .{ }^{14)}$ considered the effect of average dislocation density and the dislocation interaction parameter on YS, and concluded that the dislocation contribution is estimated to be 115 and $52 \mathrm{MPa}$ in the as-rolled and as-annealed conditions, respectively. Based on this, the dislocation density contribution without annealing is estimated to be $63 \mathrm{MPa}$. When this value of $63 \mathrm{MPa}$ is subtracted from the YS data for the present Uf-F/C, the corrected YS value for the annealed one becomes $473 \mathrm{MPa}$. This is in good agreement with the above-mentioned value of $464 \mathrm{MPa}$ because the grain size is supposed to be $2.7 \mu \mathrm{m}$.

Therefore, the grain size determining YS is the average grain size for the Uf-F/C, although the $d_{\mathrm{EFF}}$ determining the DBTT corresponds to the larger size in the two-grain clusters. This result might be very much disputable; however,

Table 3. Properties of the steel with different microstructures, i.e. ferrite/pearlite (F/P), ultra-fine ferrite/cementite (Uf-F/C), asquenched (Q), and quench-and-tempered (QT) steels: $d_{\mathrm{EFF}}$ (effective grain size), unit determining the $d_{\mathrm{EFF}}$, YS (yield strength), $\sigma_{\mathrm{F}}$ (fracture strength), DBTT (ductile-to-brittle transition temperature), and $\gamma$ (surface energy).

\begin{tabular}{|c|c|c|c|c|c|c|}
\hline Sample & $\begin{array}{c}\mathrm{d}_{\mathrm{EFF}} \\
(\mu \mathrm{m})\end{array}$ & $\begin{array}{c}\text { Unit } \\
\text { determining } \mathrm{d}_{\mathrm{EFF}}\end{array}$ & $\begin{array}{c}\mathrm{YS}(\mathrm{MPa}) \\
\text { Experimental }\end{array}$ & $\begin{array}{c}\mathrm{FS}(\mathrm{MPa}) \\
\text { Estimated }\end{array}$ & $\begin{array}{c}\mathrm{DBTT}(\mathrm{K}) \\
\text { Experimental }\end{array}$ & $\begin{array}{c}\gamma\left(\mathrm{J} / \mathrm{m}^{2}\right) \\
\text { Estimated }\end{array}$ \\
\hline F/P & 20 & Ferrite grain & 261 & 351 & 223 & 7.7 \\
\hline Uf-F/C & 8 & $\begin{array}{c}\text { Bigger part in } \\
\text { grain clusters }\end{array}$ & 536 & 1066 & 53 & \multirow{2}{*}{34.6} \\
\hline QT & 25 & $\begin{array}{c}\text { Martensite } \\
\text { packet }\end{array}$ & 548 & 620 & 253 & 150.9 \\
\hline Q & 100 & $\begin{array}{c}\text { Prior-austenite } \\
\text { grain }\end{array}$ & 619 & 619 & 378 & \multirow{2}{*}{} \\
\hline
\end{tabular}


more improvement in the YS-DBTT balance can be expected from the present results. Further detailed studies are required for this purpose.

\section{Conclusions}

To investigate the excellent toughness of ultrafine ferrite/cementite steels, the concept of effective grain size $\left(d_{\mathrm{EFF}}\right)$ is applied to ductile-to-brittle transition temperature, DBTT, for four different microstructures in one composition of low carbon steel. The microstructures are ultra-fine ferrite/cementite (Uf-F/C), ferrite/pearlite (F/P), quenched (Q), and quench-and-tempered (QT). The following conclusions are obtained.

(1) For Uf-F/C, F/P, Q, and QT, the $d_{\mathrm{EFF}}$ is determined to be $8,20,100$, and $25 \mu \mathrm{m}$, respectively. In F/P and Q, the $d_{\mathrm{EFF}}$ is in accordance with the ferrite grain size and the prior austenite size, respectively. The $d_{\mathrm{EFF}}$ for QT corresponds to the martensite packet size. In Uf-F/C the ferrite grain size has a bimodal distribution and the larger grain size matches the $d_{\mathrm{EFF}}$, the smallest among the four microstructures.

(2) The relationship between $d_{\mathrm{EFF}}$ and DBTT reveals that the Uf-F/C microstructure belongs to the same group composed of Q and QT microstructures, and F/P belongs to a different group.

(3) The estimated fracture stress shows that Uf-F/C has the highest fracture stress among the four microstructures.

(4) The difference in DBTT and $\sigma_{\mathrm{F}}$ among the four microstructures is estimated to be the difference in the surface energy of fracture. The group of Uf-F/C and QT has a much higher surface energy value than that for the $F / P$ group.

(5) The excellent toughness of the ultrafine ferrite/cementite steel can be attributed to its characteristic small $d_{\mathrm{EFF}}$ and high surface energy of fracture, compared to those of other structures.

\section{Acknowledgments}

The authors thank Dr. Kaneaki Tsuzaki, Dr. Shiro
Torizuka, Mr. Hiroshi Nakajima, Mr. Nobuo Sakuma, Mr. Masashi Saito, Mr. Katsuya Ohnishi, Mr. Tohru Awane, Mr. Takaaki Hibaru, Ms. Tomoko Nozawa, Ms. Lan Huang, and Ms. Elena Bulgarevich for their technical help and scientific discussions.

\section{REFERENCES}

1) F. B. Pickering and T. Gladman: Iron Steel Inst. Spec. Rep., (1963), No. $81,10$.

2) A. H. Cottrell: Trans. Metall. Soc. AIME, 212 (1958), 192.

3) N. J. Petch: Philos. Mag., 3 (1958), 1089.

4) A. N. Stroh: Adv. Phys., 6 (1957), 48.

5) T. Hanamura, T. Hayashi, H. Nakajima, S. Torizuka and K. Nagai: Second Int. Conf. on Processing Materials for Properties, ed. by B. Mishra and C. Yamauchi, TMS, Warrendale, PA, (2000), 206.

6) W. C. Leslie: Metall. Trans., 3-5 (1972).

7) J. M. Hodge, R. D. Manning and H. M. Richhold: Trans. AIME, 185-233 (1949).

8) S. Matsuda, T. Inoue and M. Ogasawara: Trans. Jpn. Inst. Met., 9 (1968), 343, 11 (1970), 36.

9) F. Terasaki and H. Ohtani: Tetsu-to-Hagané, 58 (1972), 436.

10) F. Terasaki and H. Ohtani: Trans. Iron Steel Inst. Jpn., 12 (1972), 45.

11) C. D. Beachem: Metall. Trans., 4 (1973), 1999.

12) S. Matsuda, T. Inoue, H. Mimura and Y. Okamura: Trans. Iron Steel Inst. Jpn., 12 (1972), 325.

13) C. D. Beachem: Fracture, Vol. I, Academic Press, New York and London, (1968), 305.

14) F. Yin, T. Hanamura, T. Inoue and K. Nagai: Seventh Workshop on the Ultra-Steel: Requirements from New Design of Constructions, NIMS, Tsukuba, (2003), 288.

15) F. Terasaki and H. Ohtani: Tetsu-to-Hagané, 58 (1972), 1067.

16) K. Nagai and O. Umezawa: Report of Study Committee on Effect of Impurities due to Scrap on Steel Products, Materials Science of Tramp Elements, ISIJ, Tokyo, (1997), 70.

17) A. A. Griffith: Philos. Trans. R. Soc. (London) A, $\mathbf{A 2 2 1}$ (1920), 163.

18) N. Tsuchida, Y. Tomoda and K. Nagai: ISIJ Int., 42 (2002), 1594.

19) A. Kelly et al.: Philos. Mag., 15 (1967), 567.

20) T. Yokobori: Tech. Rep. Tohoku Univ., 29 (1964), 167.

21) H. Yagi, N. Tsuji and Y. Saito: Tetsu-to-Hagané, 86 (2000), 349.

22) A. Ohmori, S. Torizuka, K. Nagai, K. Yamada and Y. Kogo: Tetsu-toHagané, 88 (2002), 857.

23) N. Tsuchida, Y. Tomoda and K. Nagai: Tetsu-to-Hagané, 89 (2003), 1170 . 